\title{
Hypothermic total liquid ventilation after experimental aspiration-associated acute respiratory distress syndrome
}

Jérôme Rambaud ${ }^{1,2}$, Fanny Lidouren'1, Michaël Sage ${ }^{3}$, Matthias Kohlhauer ${ }^{1}$, Mathieu Nadeau³, Étienne Fortin-Pellerin ${ }^{3}$, Philippe Micheau ${ }^{3}$, Luca Zilberstein ${ }^{1}$, Nicolas Mongardon ${ }^{1,4}$, Jean-Damien Ricard ${ }^{5}$, Megumi Terada ${ }^{6}$, Patrick Bruneval ${ }^{6}$, Alain Berdeaux ${ }^{1}$, Bijan Ghaleh ${ }^{1}$, Hervé Walti ${ }^{1}$ and Renaud Tissier $^{1 *}$ (D)

\begin{abstract}
Background: Ultrafast cooling by total liquid ventilation (TLV) provides potent cardio- and neuroprotection after experimental cardiac arrest. However, this was evaluated in animals with no initial lung injury, whereas out-of-hospital cardiac arrest is frequently associated with early-onset pneumonia, which may lead to acute respiratory distress syndrome (ARDS). Here, our objective was to determine whether hypothermic TLV could be safe or even beneficial in an aspiration-associated ARDS animal model.
\end{abstract}

Methods: ARDS was induced in anesthetized rabbits through a two-hits model including the intra-tracheal administration of a $\mathrm{pH}=1$ solution mimicking gastric content and subsequent gaseous non-protective ventilation during $90 \mathrm{~min}$ (tidal volume $[\mathrm{Vt}]=10 \mathrm{ml} / \mathrm{kg}$ with positive end-expiration pressure $[\mathrm{PEEP}]=0 \mathrm{cmH}_{2} \mathrm{O}$ ). After this initial period, animals either received lung protective gas ventilation ( $\mathrm{LPV} ; \mathrm{Vt}=8 \mathrm{ml} / \mathrm{kg}$ and $\left.\mathrm{PEEP}=5 \mathrm{cmH}_{2} \mathrm{O}\right)$ under normothermic conditions, or hypothermic TLV (TLV; Vt $=8 \mathrm{ml} / \mathrm{kg}$ and end-expiratory volume $=15 \mathrm{ml} / \mathrm{kg}$ ). Both strategies were applied for 120 min with a continuous monitoring of respiratory and cardiovascular parameters. Animals were then euthanized for pulmonary histological analyses.

Results: Eight rabbits were included in each group. Before randomization, all animals elicited ARDS with arterial oxygen partial pressure over inhaled oxygen fraction ratios $\left(\mathrm{PaO}_{2} / \mathrm{FiO}_{2}\right)$ below $100 \mathrm{mmHg}$, as well as decreased lung compliance. After randomization, body temperature rapidly decreased in TLV versus LPV group (32.6 \pm 0.6 vs. $38.2 \pm 0.4^{\circ} \mathrm{C}$ after $15 \mathrm{~min}$ ). Static lung compliance and gas exchanges were not significantly different in the TLV versus LPV group $\left(\mathrm{PaO}_{2} / \mathrm{FiO}_{2}=62 \pm 4\right.$ vs. $52 \pm 8 \mathrm{mmHg}$ at the end of the procedure, respectively). Mean arterial pressure and arterial bicarbonates levels were significantly higher in TLV versus LPV. Histological analysis also showed significantly lower inflammation in TLV versus LPV group (median histological score $=3$ vs. 4.5/5, respectively; $p=0.03$ ).

Conclusion: Hypothermic TLV can be safely induced in rabbits during aspiration-associated ARDS. It modified neither gas exchanges nor respiratory mechanics but reduced lung inflammation and hemodynamic failure in comparison with LPV. Since hypothermic TLV was previously shown to provide neuro- and cardio protective effects after cardiac arrest, these findings suggest a possible use of TLV in the settings of cardiac arrest-associated ARDS.

Keywords: ARDS, Pneumonia, Aspiration, Total liquid ventilation, Hypothermia, Cardiac arrest

\footnotetext{
${ }^{*}$ Correspondence: renaud.tissier@vet-alfort.fr

1 U955 - IMRB, Inserm, UPEC, Ecole Nationale Vétérinaire d'Alfort,

7 avenue du Général de Gaulle, 94700 Maisons-Alfort, France

Full list of author information is available at the end of the article
}

Springer Open

C The Author(s) 2018. This article is distributed under the terms of the Creative Commons Attribution 4.0 International License (http://creativecommons.org/licenses/by/4.0/), which permits unrestricted use, distribution, and reproduction in any medium, provided you give appropriate credit to the original author(s) and the source, provide a link to the Creative Commons license, and indicate if changes were made. 


\section{Background}

After out-of-hospital cardiac arrest and successful resuscitation, a post-cardiac arrest syndrome occurs and makes patients prone to infectious complications $[1,2]$. Among them, early-onset pneumonia affects up to twothirds of successfully resuscitated patients and are mainly related to aspiration. In this setting, aspiration pneumonia deteriorates pulmonary function and has negative impact on outcome [1-3]. More dramatically, aspiration pneumonia can culminate into acute respiratory distress syndrome (ARDS). For instance, around six percent of the patients resuscitated after out-of-hospital cardiac arrest present ARDS [4-6].

Hypothermic total liquid ventilation (TLV) could be an interesting alternative to conventional ventilation in the context of cardiac arrest-associated aspiration pneumonia since this technique has been previously shown to limit the post-cardiac arrest syndrome in animal studies [7-11]. During TLV, the lungs can be alternatively filled and emptied by perfluorocarbons, authorizing lung lavage as well as gas and thermal exchanges. This approach provides ultrafast cooling [12] and powerful neuro- and cardioprotection after cardiac arrest, as well as attenuation of multi-organ dysfunction after low perfusion states [7-11].

In the context of aspiration-associated ARDS, hypothermic TLV might also provide benefits per se through lung lavage or anti-inflammatory effects of liquid ventilation [13-18]. Conversely, one would also argue that TLV could increase the risk of ventilation-induced injury when initiated after such lung injury. Our previous reports with hypothermic TLV were indeed done in animal models of cardiac with very controlled conditions preventing accidental aspiration. Accordingly, the goal of the present study was to investigate whether TLV could be safely induced in a model of aspiration-associated ARDS and whether it modifies gas exchanges, respiratory mechanics, hemodynamic status or pulmonary inflammatory response in rabbits.

\section{Methods}

The animal instrumentation and the ensuing experiments were approved by the institutional review board for animal research (project 04585-04 evaluated by the "Ethical committee Anses-Enva-UPEC").

\section{Animal instrumentation}

Male New Zealand rabbits $(2.5-3.5 \mathrm{~kg})$ were anesthetized using zolazepam, tiletamine and pentobarbital (all 20-30 $\mathrm{mg} / \mathrm{kg}$ i.v.). After intubation, they were artificially ventilated with inspired fraction of oxygen $\left(\mathrm{FiO}_{2}\right)$ of $30 \%$ (SAR-830P, CWE Inc., Ardmore, USA). Tidal volume was set at $8 \mathrm{~mL} / \mathrm{kg}$ and respiratory rate at 30 cycles/ min. Positive end-expiratory pressure (PEEP) was set at $5 \mathrm{cmH}_{2} \mathrm{O}$. Peripheral catheters were inserted into the ear marginal vein and artery for blood sampling and pressure monitoring, respectively. Temperature probes were also inserted into the rectum and esophagus. Anesthesia was maintained with additional administration of pentobarbital (5 mg/kg/h i.v.).

\section{Experimental protocol}

After stabilization, rabbits were paralyzed by vecuronium bromide $(0.4 \mathrm{mg} / \mathrm{kg} / \mathrm{h}$, i.v.). ARDS was induced with a two-hits injury including an intra-tracheal administration of $4 \mathrm{ml} / \mathrm{kg}$ of an aqueous solution at $\mathrm{pH}=1$ and a period of conventional non-protective gas ventilation. The acid solution was administered slowly into the tracheal tube, while animals were manipulated in order to improve lung distribution. Conventional non-protective ventilation consisted in mechanical ventilation with tidal volumes set at $10 \mathrm{ml} / \mathrm{kg}$ and PEEP at $0 \mathrm{cmH}_{2} \mathrm{O}$. Inhaled fraction of oxygen $\left(\mathrm{FiO}_{2}\right)$ was increased to $100 \%$. Conventional non-protective ventilation was maintained during 90 min according to preliminary experiments demonstrating an optimal balance between the occurrence of reproducible ARDS and the need for a sufficient survival and follow-up after group allocation. Body temperature was maintained around $38.5^{\circ} \mathrm{C}$ throughout ARDS induction phase.

After the period of conventional ventilation, animals were randomly allocated to a group treated by lung protective gas ventilation (LPV) or TLV for $120 \mathrm{~min}$ (Fig. 1). In the LPV group, tidal volume was set at $8 \mathrm{ml} / \mathrm{kg}$ with $\mathrm{PEEP}=5 \mathrm{cmH}_{2} \mathrm{O}$. Such tidal volumes used are slightly higher that the recommended volumes for humans with ARDS. However, lower tidal volumes are currently recommended in rabbits. Body temperature was maintained at $38.5{ }^{\circ} \mathrm{C}$ using heating pads in the LPV group. In the TLV group, animals were ventilated with a dedicated prototype of liquid ventilator continuously controlling liquid pressures and volumes (Inolivent-5, Université de Sherbrooke, QC, Canada) [16, 19]. They were submitted to hypothermia with a target temperature of $33{ }^{\circ} \mathrm{C}$ [7-11, 20, 21]. Lungs were initially filled with $13 \mathrm{ml} / \mathrm{kg}$ of perfluoro-n-octane (PFO, C8F18; F2-chemical ${ }^{\circledR}$, Preston, Lancashire, UK). Tidal volume was set at 8-10 ml/ $\mathrm{kg}$ and respiratory frequency at $9 \mathrm{cycles} / \mathrm{min}$. The pulmonary end-expiratory volumes of PFO were increased to reach $15-20 \mathrm{ml} / \mathrm{kg}$. The temperature of the liquid was initially set at $20^{\circ} \mathrm{C}$ and progressively increased in order to maintain body core temperature at $33{ }^{\circ} \mathrm{C}$. Static lung compliance was calculated by dividing tidal volume by the difference between airways pressures between end-inspiratory and end-expiratory pauses. Pause pressures were calculated after valve closures at the end of 


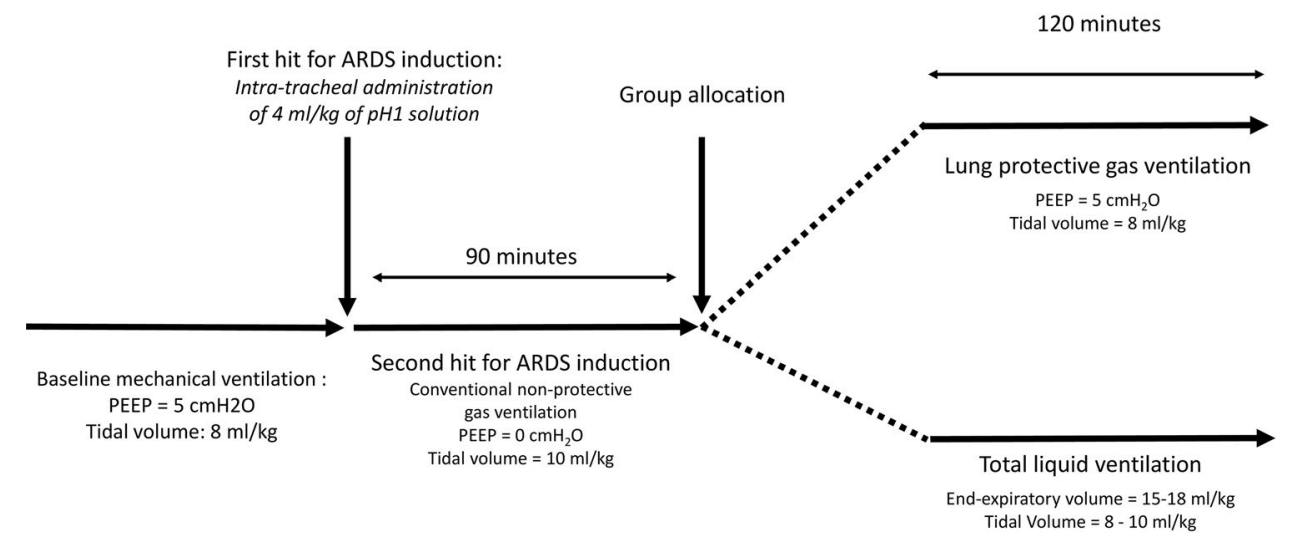

Fig. 1 Schematic representation of the experimental protocol. ARDS acute respiratory distress syndrome; PEEP positive end-expiratory pressure

inspiration and expiration, respectively. Mean values were obtained with at least 3 cycles. After $120 \mathrm{~min}$ of LPV or TLV, animals were weaned back to conventional gas ventilation. Both groups were submitted to bronchoalveolar lavage at the end of the protocol for the further evaluation of albumin content. Immediately after broncho-alveolar lavage, animals were then euthanized using a lethal dose of pentobarbital $(60 \mathrm{mg} / \mathrm{kg}$ iv). Lungs were collected, perfused and fixed with formaldehyde (4\%) for histological analysis.

\section{Investigational parameters}

Throughout the procedure, heart rate and arterial blood pressure were continuously monitored (HEM version 4.2, Notocord, Croissy-sur-Seine, France), as well as esophagus and rectal temperatures. Arterial blood samples were withdrawn at baseline, after ARDS induction and 30 and 120 min after the onset of LPV or TLV for the evaluation of arterial $\mathrm{pH}$, bicarbonates blood levels, partial pressures of oxygen $\left(\mathrm{PaO}_{2}\right)$ and carbon dioxide $\left(\mathrm{PaCO}_{2}\right)$. Blood levels of interleukin $1 \beta$ were also evaluated (ELISA Kit for interleukin 1 beta, SEA563Rb, Cloud-Clone, Katy, TX, USA). Albumin concentration was evaluated in the broncho-alveolar lavage solution.

In addition, lungs were prepared for histological analysis, as previously described [9]. The severity of ARDS lesions was assessed by a pathologist blinded to the experimental group. Two separate scores were attributed to each lung after the evaluation of all pulmonary lobes, i.e., one score for the magnitude of lung congestion and edema $(0=$ normal histological appearance; $5=$ extensive congestion and edema in the entire lung) and one score for inflammatory lesions $(0=$ normal histological appearance; $5=$ extensive leukocytic alveolitis with haline membranes), respectively.

\section{Statistical analysis}

Data were expressed as mean \pm SEM. Hemodynamic, respiratory and biochemical variables were compared between groups using a two-way ANOVA for repeated measures followed by a post hoc Holm-Sidak test if necessary. In order to reduce the number of comparisons, post hoc comparisons were performed between groups for each time point but not between time points within the same group. Histological scores were compared between groups using a Mann-Whitney $U$ test. Significant differences were determined at $p$ value $\leq 0.05$.

\section{Results}

Baseline characteristics and ARDS induction

Eight rabbits were included in each LPV and TLV groups. As shown in Tables 1 and 2, no difference was observed at baseline among groups regarding body weight $(3.1 \pm 0.1$ vs. $3.1 \pm 0.1 \mathrm{~kg}$, respectively), body temperature, hemodynamic or blood biochemical parameters. At the end of the conventional non-protective ventilation period, typical signs of ARDS were observed in both groups, including decreased lung compliance and decreased $\mathrm{PaO}_{2} / \mathrm{FiO}_{2}$ ratios with no difference between groups. The latter ratio achieved $41 \pm 5$ and $51 \pm 9 \mathrm{mmHg}$ at the end of the conventional ventilation period in LPV and TLV groups, as compared to $755 \pm 97$ and $730 \pm 150 \mathrm{mmHg}$ at baseline, respectively. $\mathrm{FiO}_{2}$ was maintained at $100 \%$ in all animals after ARDS induction.

\section{Effect of TLV on gas exchanges, airways pressures, lung volumes and compliance}

As shown in Table 2, blood oxygen saturation, $\mathrm{pH}$, $\mathrm{PaO}_{2}$ and $\mathrm{PaCO}_{2}$ were not significantly different during TLV versus LPV. The $\mathrm{PaO}_{2} / \mathrm{FiO}_{2}$ ratio remained below $100 \mathrm{mmHg}$ during the experimental protocol in both groups. This ratio achieved $52 \pm 8$ and $62 \pm 4 \mathrm{mmHg}$ in 
Table 1 Hemodynamic parameters and temperatures throughout protocol in rabbits presenting experimental acute respiratory distress syndrome and treated by gaseous lung protective ventilation (LPV) or total liquid ventilation (TLV), respectively

\begin{tabular}{|c|c|c|c|c|c|c|}
\hline \multirow[t]{2}{*}{ Parameters and groups } & \multirow[t]{2}{*}{ Baseline } & \multicolumn{2}{|c|}{ Conventional ventilation } & \multicolumn{3}{|l|}{ LPV or TLV } \\
\hline & & $15 \mathrm{~min}$ & $90 \mathrm{~min}$ & $10 \mathrm{~min}$ & $60 \mathrm{~min}$ & $120 \mathrm{~min}$ \\
\hline \multicolumn{7}{|l|}{ Esophageal temperature $\left({ }^{\circ} \mathrm{C}\right)$} \\
\hline LPV & $38.7 \pm 0.5$ & $38.1 \pm 0.6$ & $38.2 \pm 0.4$ & $38.2 \pm 0.4$ & $38.6 \pm 0.4$ & $38.6 \pm 0.4$ \\
\hline TLV & $38.5 \pm 0.8$ & $38.0 \pm 0.8$ & $38.8 \pm 0.5$ & $32.6 \pm 0.6^{*}$ & $33.1 \pm 0.3^{*}$ & $33.2 \pm 0.2^{*}$ \\
\hline \multicolumn{7}{|l|}{ Rectal temperature $\left({ }^{\circ} \mathrm{C}\right)$} \\
\hline LPV & $38.7 \pm 0.5$ & $38.1 \pm 0.6$ & $38.2 \pm 0.4$ & $38.3 \pm 0.3$ & $38.4 \pm 0.3$ & $38.4 \pm 0.4$ \\
\hline TLV & $38.7 \pm 0.5$ & $37.8 \pm 0.9$ & $39.1 \pm 0.4$ & $34.8 \pm 0.5^{*}$ & $33.0 \pm 0.2^{*}$ & $33.0 \pm 0.1^{*}$ \\
\hline \multicolumn{7}{|l|}{ Heart rate (beats/min) } \\
\hline LPV & $257 \pm 18$ & $233 \pm 16$ & $246 \pm 17$ & $255 \pm 17$ & $248 \pm 15$ & $253 \pm 7$ \\
\hline TLV & $242 \pm 17$ & $242 \pm 17$ & $262 \pm 15$ & $171 \pm 6^{*}$ & $172 \pm 6^{*}$ & $165 \pm 7^{*}$ \\
\hline \multicolumn{7}{|c|}{ Mean arterial blood pressure $(\mathrm{mmHg})$} \\
\hline LPV & $75 \pm 7$ & $74 \pm 6$ & $65 \pm 6$ & $67 \pm 5$ & $61 \pm 4$ & $56 \pm 8$ \\
\hline TLV & $69 \pm 5$ & $73 \pm 3$ & $65 \pm 5$ & $69 \pm 6$ & $82 \pm 6^{*}$ & $74 \pm 9^{*}$ \\
\hline \multicolumn{7}{|c|}{ Lung compliance $\left(\mathrm{ml} / \mathrm{kg} / \mathrm{cmH}_{2} \mathrm{O}\right)$} \\
\hline LPV & $0.99 \pm 0.11$ & $0.59 \pm 0.10$ & $0.56 \pm 0.09$ & $0.78 \pm 0.16$ & $0.78 \pm 0.16$ & $0.65 \pm 0.10$ \\
\hline TLV & $1.09 \pm 0.18$ & $0.61 \pm 0.07$ & $0.63 \pm 0.09$ & $0.74 \pm 0.09$ & $0.71 \pm 0.07$ & $0.67 \pm 0.06$ \\
\hline
\end{tabular}

Statistical comparisons were only made for group effect but not among time points

$n=8$ in each LPV and TLV group

${ }^{*} p<0.05$ versus LPV

Table 2 Biochemical characteristics throughout protocol in rabbits presenting experimental acute respiratory distress syndrome and treated by gaseous lung protective ventilation (LPV) or total liquid ventilation (TLV), respectively

\begin{tabular}{|c|c|c|c|c|}
\hline \multirow[t]{2}{*}{ Parameters and groups } & \multirow[t]{2}{*}{ Baseline } & \multirow[t]{2}{*}{ Conventional ventilation $(t=90 \mathrm{~min})$} & \multicolumn{2}{|l|}{ LPV or TLV } \\
\hline & & & $30 \mathrm{~min}$ & $120 \mathrm{~min}$ \\
\hline \multicolumn{5}{|l|}{ Arterial blood saturation (\%) } \\
\hline LPV & $100 \pm 0$ & $76 \pm 4$ & $62 \pm 9$ & $80 \pm 5$ \\
\hline TLV & $100 \pm 0$ & $73 \pm 3$ & $83 \pm 12$ & $90 \pm 2$ \\
\hline \multicolumn{5}{|l|}{ Arterial blood pH } \\
\hline LPV & $7.36 \pm 0.03$ & $7.15 \pm 0.06$ & $7.14 \pm 0.15$ & $7.18 \pm 0.05$ \\
\hline TLV & $7.35 \pm 0.04$ & $7.22 \pm 0.02$ & $7.17 \pm 0.04$ & $7.16 \pm 0.04$ \\
\hline \multicolumn{5}{|l|}{ Arterial blood $\mathrm{PaO}_{2}(\mathrm{mmHg})$} \\
\hline LPV & $227 \pm 29$ & $41 \pm 5$ & $62 \pm 9$ & $52 \pm 8$ \\
\hline TLV & $219 \pm 38$ & $51 \pm 9$ & $83 \pm 12$ & $62 \pm 4$ \\
\hline \multicolumn{5}{|c|}{ Arterial blood $\mathrm{PaO}_{2} / \mathrm{FiO}_{2}(\mathrm{mmHg})$} \\
\hline LPV & $755 \pm 97$ & $41 \pm 5$ & $62 \pm 9$ & $52 \pm 8$ \\
\hline TLV & $730 \pm 150$ & $51 \pm 9$ & $83 \pm 12$ & $62 \pm 4$ \\
\hline \multicolumn{5}{|c|}{ Arterial blood $\mathrm{PaCO}_{2}(\mathrm{mmHg})$} \\
\hline LPV & $47 \pm 3$ & $70 \pm 11$ & $68 \pm 7$ & $67 \pm 7$ \\
\hline TLV & $49 \pm 6$ & $72 \pm 4$ & $80 \pm 5$ & $79 \pm 4$ \\
\hline \multicolumn{5}{|c|}{ Bicarbonate blood level (mmol/l) } \\
\hline LPV & $28 \pm 2$ & $24 \pm 2$ & $23 \pm 1$ & $24 \pm 2$ \\
\hline TLV & $28 \pm 1$ & $29 \pm 2$ & $30 \pm 1^{*}$ & $31 \pm 2^{*}$ \\
\hline
\end{tabular}

Statistical comparisons were only made for group effect but not among time points

$n=8$ in each LPV and TLV group; FiO2, inhaled fraction of oxygen

${ }^{*} p<0.05$ versus LPV 


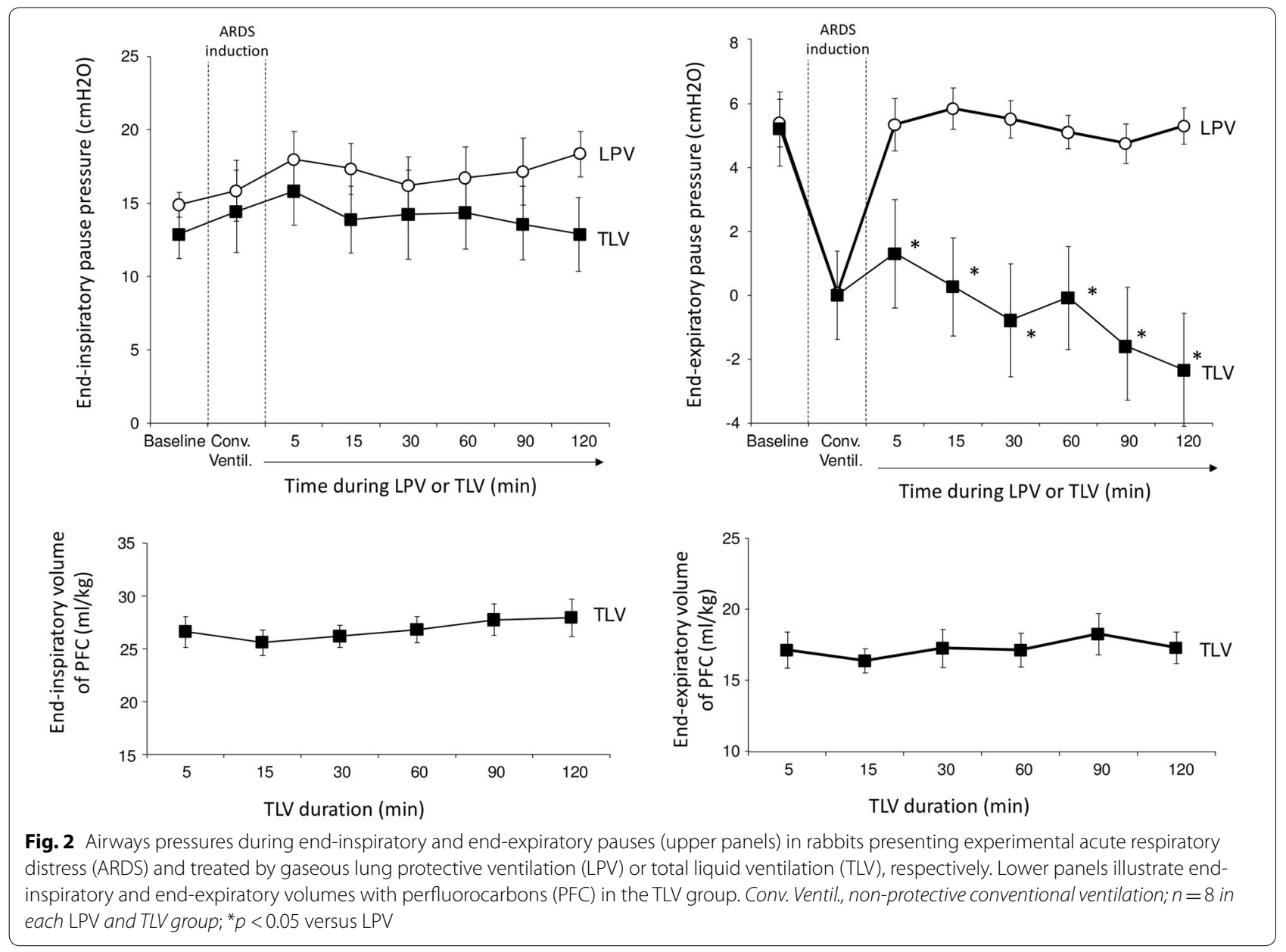

the LPV and TLV groups, evidencing similar severity of ARDS in both conditions.

As shown in Fig. 2, end-inspiratory and expiratory airway pressures tended to decrease during TLV as compared to LPV. This difference was not statistically different for end-inspiratory pressures $(p=0.08)$ but only for end-expiratory pressures $\left(5.3 \pm 0.6\right.$ vs. $-2.4 \pm 1.6 \mathrm{cmH}_{2} \mathrm{O}$ at the end of the procedure, $p<0.001)$. Lung compliance was not significantly different between these two groups (Table 1). In the TLV group, lung liquid volumes averaged $25-30$ and $15-20 \mathrm{ml} / \mathrm{kg}$ at the end of expiratory and inspiratory period (Fig. 2), respectively.

\section{Effect of hypothermic TLV on temperature, hemodynamic and bicarbonate blood levels}

As shown in Table 1, body temperatures decreased very rapidly after TLV initiation as compared to LPV. This was associated with a decreased heart rate, as well as improved systemic arterial pressure. Mean arterial pressure achieved $74 \pm 9$ versus $56 \pm 8 \mathrm{mmHg}$ at the end of the procedure period in the TLV vs. LPV groups $(p<0.05)$, respectively. As shown in Table 2, the drop in bicarbonates arterial levels was also significantly attenuated by hypothermia in the TLV group as compared to LPV. Bicarbonates arterial levels achieved $31 \pm 2$ versus $24 \pm 2 \mathrm{mmol} / \mathrm{l}$ in TLV versus LPV at the end of the protocol $(p=0.007)$.

\section{Effect of hypothermic TLV on inflammatory response assessed by broncho-alveolar lavage and lung histology} At the end of the protocol, the protein content of the broncho-alveolar lavage solution was similar between groups $(351 \pm 11$ vs. $334 \pm 13 \mu \mathrm{g} / \mathrm{ml}$ in TLV vs. LPV groups, respectively). Conversely, the concentration in interleukin-1 $\beta$ tended to decrease in TLV versus LPV, but the difference was not significant $(7.1 \pm 0.7$ vs $11.2 \pm 2.5 \mathrm{pg} / \mathrm{ml} ; p=0.08)$.

After completion of the protocol, typical signs of ARDS were observed in all animals at lung histology. As illustrated in Fig. 3a, we observed moderate to severe leukocytic alveolitis and intra-alveolar red blood cells infiltration in all animals in the LPV group. Two animals 

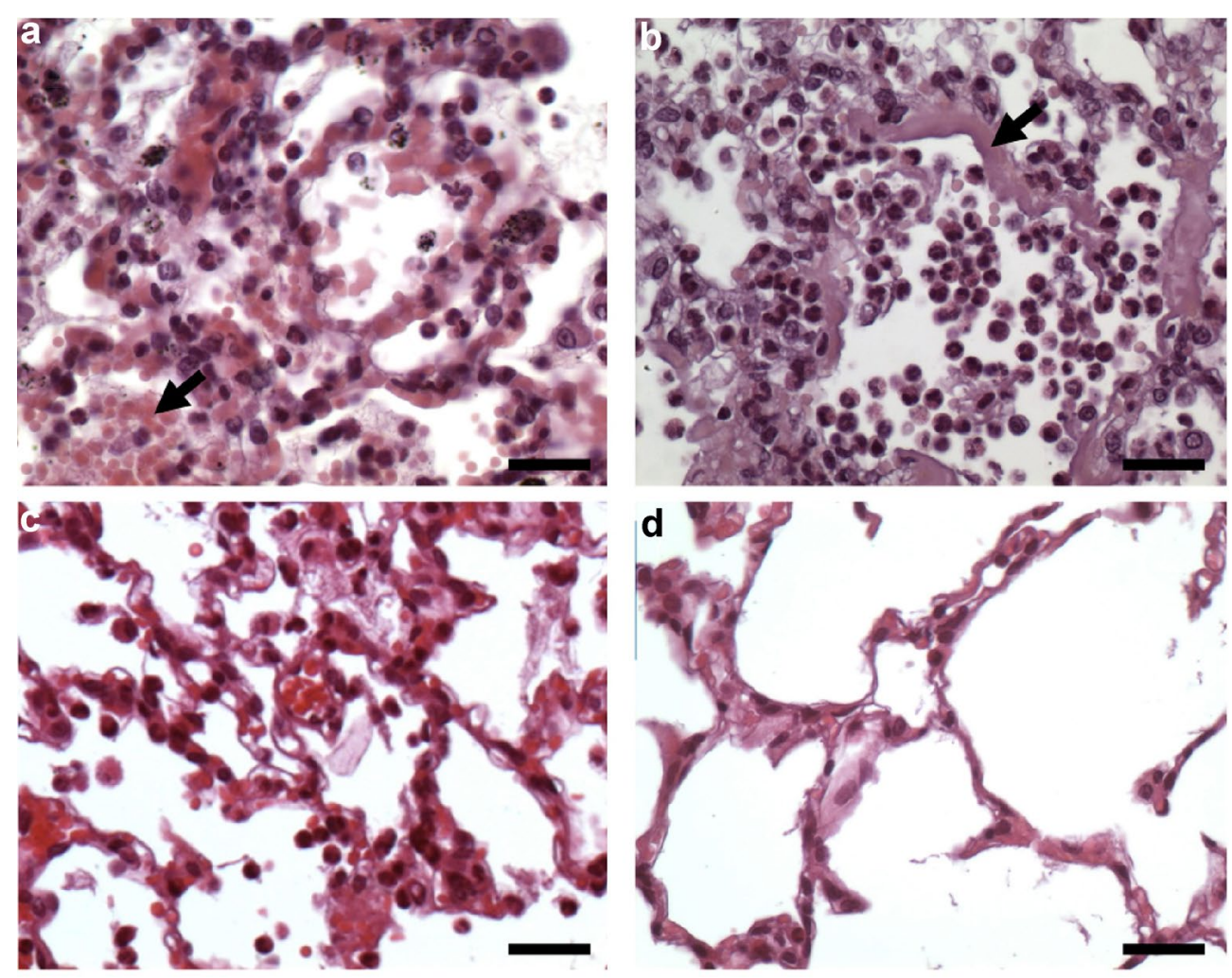

e

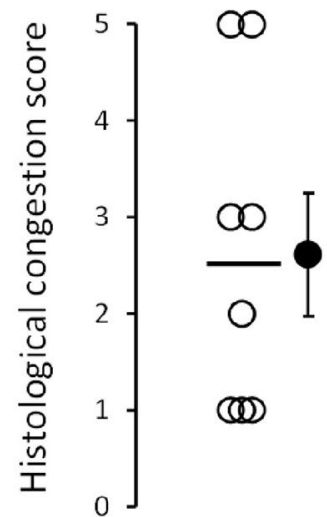

LPV

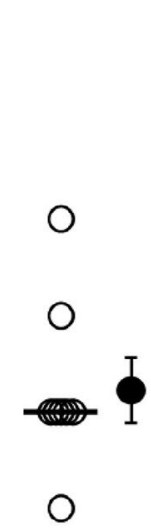

TLV

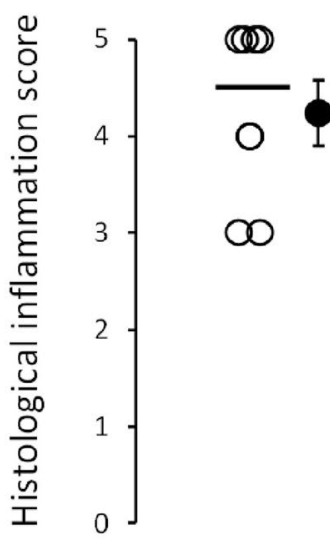

LPV
(8)

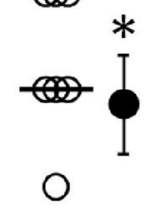

O

TLV

Fig. 3 Histological appearance of the lungs in the group submitted to gaseous lung protective ventilation (LPV) or total liquid ventilation (TLV). a Histological appearance of the lung in a rabbit from the LPV group with leukocytic alveolitis and severe congestion, evidenced by intra-alveolar red blood cells infiltration (arrow; Bar $=25 \mu \mathrm{m}$ ). b Severe lesions of leukocytic alveolitis in a rabbit from the LPV group. The arrow illustrates hyaline membranes, as a marker of severe alveolar lesions $(B a r=25 \mu \mathrm{m})$. $\mathbf{c}$ Histological appearance of the lung in a rabbit from the TLV group with moderate alveolitis and congestion $(\mathrm{Bar}=25 \mu \mathrm{m})$. d Normal histological appearance of the lung in a rabbit from the TLV group $(B a r=25 \mu \mathrm{m})$. e Histological scores of the severity of the congestive and inflammatory lesions in the different groups ( $n=8$ in each LPV and TLV group). Open circles represent the individual value of each animal, and the bold line illustrates the median score of each group, respectively. Closed circles represent mean and standard of the mean of each group. ${ }^{*} p<0.05$ versus LPV

also presented alveolar hyaline membranes, evidencing major ARDS lesions in this group. In the TLV group, lungs showed normal appearance in one animal and mild to severe inflammation and congestion in others. As shown in Fig. 3e, the blindly attributed score of inflammation was significantly reduced in TLV versus LPV group (median score $=3$ vs. 4.5 , respectively; $p=0.03$ ). Conversely, the score attributed for congestion severity 
was not significantly different among groups (median score $=1$ vs. $2.5 ; p=0.08$ ).

\section{Discussion}

In the present study, hypothermic TLV did not modify gas exchange and lung compliance but attenuated hemodynamic failure and lung inflammation in a model of experimental aspiration-associated ARDS in rabbits. These demonstrations were obtained with a last-generation liquid ventilator which accurately controls lung volumes and pressures during TLV [13]. Importantly, the design of the study does not able to differentiate the effect of TLV from hypothermia since we investigated the effect of hypothermic TLV. Our ultimate goal is indeed to translate hypothermic TLV from the bench side to human practice for the treatment of the post-cardiac arrest syndrome [7-11].

Importantly, there are apparently conflicting results regarding the effect of liquid ventilation during ARDS in the literature. In 2006, Kacmarek et al. [22] demonstrated that partial liquid ventilation did not improve outcome as compared to conventional mechanical ventilation and recommended against its use in ARDS patients. In the latter study, partial liquid ventilation was performed after lung filling with $10 \mathrm{ml} / \mathrm{kg}$ or $20 \mathrm{ml} / \mathrm{kg}$ of perflubron, with high values of positive end-expiratory pressure (13 $\mathrm{cmH} 2 \mathrm{O}$ ) and relatively high tidal volumes for gas ventilation $(\approx 8-10 \mathrm{ml} / \mathrm{kg})$. In addition, patients were repeatedly derecruited by abrupt decreases in PEEP from 13 to $0 \mathrm{cmH}_{2} \mathrm{O}$, with putative air trapping [23]. Our strategy was completely different as we performed TLV rather than partial liquid ventilation, and we used the pressure and volume-control mode of the ventilator [16]. This led to much lower and likely safer airways pressures, averaging $15 \mathrm{cmH}_{2} \mathrm{O}$ at end-inspiration, which is approximately 2 times lower than previously observed during partial liquid ventilation in ARDS patients [22]. In addition, hypothermic TLV is expected to be instituted for very short periods only to induce hypothermia after cardiac arrest, which makes it much easier to implement than prolonged liquid ventilation.

Beyond partial liquid ventilation, previous strategies of TLV were also tested in animal models of ARDS in the past. Most studies used much higher filling volume (20$30 \mathrm{ml} / \mathrm{kg})$ and tidal volume $(20-30 \mathrm{ml} / \mathrm{kg})$ than we did in the present study $[13,17,19]$. For example, Pohlmann et al. improved gas exchanges in sheep after experimental ARDS using TLV with an initial filling with $30 \mathrm{ml} /$ $\mathrm{kg}$ of perfluorocarbons, a frequency of 5 cycle per min and a tidal volume of $15-20 \mathrm{ml} / \mathrm{kg}$ during $24 \mathrm{~h}$ [17]. In another report, Avoine et al. used similar TLV parameters which improved gas exchanges after meconium aspiration [19]. However, such respiratory parameters during
TLV were associated with high pulmonary pressures, e.g., $28-30 \mathrm{cmH}_{2} \mathrm{O}$ for TLV peak pressures which might again be poorly tolerated on the longer term. In comparison, airways pressures were much lower in the present study. Lung volumes were also strongly reduced, i.e., below $15-20 \mathrm{ml} / \mathrm{kg}$ for expiratory residual volumes. Using such parameters, we were not able to improve gas exchanges as compared to LPV but a compromise should be made between the short-term need of gas exchanges improvement and the long-term hazards of lung trauma. In previous reports, we indeed demonstrated that low-volume TLV was much better tolerated regarding systemic and pulmonary hemodynamic [24]. In addition, hypothermic TLV could be done with low tidal volumes with no significant impact on gas exchanges, due to the reduced oxygen demand and carbon dioxide production during hypothermia. This is another argument in the favor of hypothermic TLV which is likely easier to implement in patients for these reasons. In the context of hypothermic TLV for post-cardiac arrest treatment, we could therefore speculate that such procedure is safe in both healthy [25] and damaged lungs after aspiration.

Interestingly, we also observed that hypothermic TLV could exert anti-inflammatory effects in the present report regarding lung histology. Such findings were already demonstrated with perfluorocarbons [26] or after experimental ARDS with other TLV devices. As example, Wolfson et al. [13] demonstrated that TLV could limit inflammation after oleic acid-induced ARDS. This could also be related to the lavage properties of TLV in a pulmonary aspiration setting. Indeed, Avoine et al. [19] demonstrated potent lavage properties of TLV in an animal model of meconial aspiration. This could open perspective for the treatment of pure ARDS, beyond the management of the post-cardiac arrest syndrome. For instance, a recent clinical study reported possible benefits with $48 \mathrm{~h}$ of cooling at $34-36^{\circ} \mathrm{C}$ in 8 ARDS patients receiving neuromuscular blockade agents [27]. In neonates, a retrospective analysis also suggested consideration of therapeutic hypothermic as an adjunctive therapy during meconial aspiration syndrome [28].

Overall, the present study further supports that hypothermic TLV could be a supplementary tool in the armamentarium against post-cardiac arrest syndrome, acting on several facets of this dreadful syndrome. In previous studies, we demonstrated potent cardiac, neuro- and renal protection after experimental cardiac arrest after both shockable $[8,11,29]$ and non-shockable rhythms [9]. More broadly, we reported strong attenuation of clinical and biological manifestations of multi-organ failure after aortic cross-clamping in a severe model of multiorgan ischemia reperfusion mimicking low perfusion states. This converges toward potent organ protection 
with hypothermic TLV after cardiac arrest, targeting the main component of the post-cardiac arrest syndrome. The current study further shows that hypothermic TLV might also be safely used after lung impairment and aspiration pneumonia, which carries specific morbidity after cardiac arrest through increased mechanical ventilation duration and ICU length of stay $[1,2]$.

Finally, this study presents several limitations. The main one is related to the experimental model which demonstrated very severe ARDS. As example, gas exchanges were dramatically altered, even after the initiation of LPV or TLV. This could explain the lack of actual benefits of TLV on gas exchanges. However, this further emphasizes that this strategy could be instituted safely even after lung injury. Importantly, the severity of ARDS in this model was previously described in rabbits submitted to $\mathrm{HCl}$-induced lung injury [30]. In the latter study, $\mathrm{PaO}_{2} /$ $\mathrm{FiO}_{2}$ ratio decreased below $100 \mathrm{mmHg}$ after $105 \mathrm{~min}$ in control conditions with conventional mechanical ventilation [30]. Another limitation is that we did not induce cardiac arrest in this model. This could have been relevant since our ultimate goal is to implement TLV in the post-resuscitation setting. The protective effect of hypothermic TLV could have been different after such global ischemia-reperfusion injury. However, since we previously tested the effect of hypothermic TLV after cardiac arrest from respiratory cause [9], we chose to focus the present study on the pulmonary effect of TLV. Finally, we did not investigate the proper effect of normothermic TLV in the present study, which could be of interest to decipher the effect of TLV by itself on inflammation and hemodynamic status, independently from the rapid temperature management induced by TLV. The investigation of another group with "slow" cooling using other methods could also be of interest to strengthen our conclusions. All these comparisons deserve further investigations.

\section{Conclusion}

In conclusions, we demonstrated that hypothermic TLV can be safely induced in rabbits during aspirationassociated ARDS. It does not improve gas exchange and lung compliance but improves hemodynamic parameters and attenuates lung inflammation. This deserves further investigation after cardiac arrest-associated ARDS.

\footnotetext{
Abbreviations

ARDS: acute respiratory distress syndrome; $\mathrm{PaO}_{2}$ : partial pressure of oxygen; $\mathrm{PaCO}_{2}$ : partial pressure of carbon dioxide; PEEP: positive end-expiratory pressure; LPV: lung protective ventilation; PFO: perfluoro-n-octane; TLV: total liquid ventilation.
}

\section{Authors' contributions}

$J R, M K, M N, E F, P M, J D R, A B, B G, H W$, RT contributed to the design of the study. $J R, F L, M S, M K, M N, L Z, M T, P B, H W, R T$ were involved in the conduct of the study. JR, FL, MN, PM, NM, JDR, PB, HW, RT analyzed the data. RT contributed to statistical analysis. All authors were involved in manuscript writing.

\section{Author details}

${ }^{1}$ U955 - IMRB, Inserm, UPEC, Ecole Nationale Vétérinaire d'Alfort, 7 avenue du Général de Gaulle, 94700 Maisons-Alfort, France. ${ }^{2}$ Paediatric and Neonatal Intensive Care Unit, Armand-Trousseau Hospital, UPMC, APHP, Paris, France. ${ }^{3}$ Université de Sherbrooke, Sherbrooke, QC, Canada. ${ }^{4}$ Service d'Anesthésie et des Réanimations Chirurgicales, DHU A-TVB, Hôpitaux Universitaires Henri Mondor, Assistance Publique des Hôpitaux de Paris, Créteil, France. ${ }^{5}$ UMR 1137, Inserm, Université Paris Diderot, Hôpital Louis Mourier, Réanimation Médico-chirurgicale, APHP, Colombes, France. ${ }^{6}$ UMR 970, Inserm, Paris Cardiovascular Research Center, Hôpital Européen Georges Pompidou, Paris, France.

\section{Acknowledgements \\ None.}

\section{Competing interests}

R Tissier and A. Berdeaux are named as inventors on a patent on cooling with liquid ventilation (US20120226337 A1). P Micheau, M Nadeau and H Walti declare owning the following patents attached to the submitted manuscript: method and apparatus for conducting total liquid ventilation with control of residual volume and ventilation cycle profile, US Patent \# 7,726,311 delivered on June 1, 2010; and indirect measurement in a total liquid ventilation system, preliminary patent in USA No 61/838,896, filled on June 25, 2013.

\section{Availability of data and materials}

The datasets used and/or analyzed during the current study are available from the corresponding author on reasonable request.

\section{Consent for publication}

All authors consent to act as authors of this publication.

\section{Ethics approval and consent to participate}

As stated in the method section of the manuscript, animal instrumentation and ensuing experiments were approved by the institutional review board for animal research (project 04585-04 evaluated par the "Ethical committee Anses-Enva-UPEC").

\section{Funding}

This study was supported by a Grant from the Region lle-de France (CORDDIM), a Grant DBS20140930781 from the "Fondation pour la Recherche Médicale" (FRM) and a Grant from the "Agence Nationale pour la Recherche" (ANR, Coolivent grant).

\section{Publisher's Note}

Springer Nature remains neutral with regard to jurisdictional claims in published maps and institutional affiliations.

Received: 28 December 2017 Accepted: 23 April 2018

Published online: 02 May 2018

References

1. Mongardon N, Perbet S, Lemiale V, Dumas F, Poupet H, Charpentier J, et al. Infectious complications in out-of-hospital cardiac arrest patients in the therapeutic hypothermia era. Crit Care Med. 2011;39:1359-64.

2. Perbet S, Mongardon N, Dumas F, Bruel C, Lemiale V, Mourvillier B, et al. Early-onset pneumonia after cardiac arrest: characteristics, risk factors and influence on prognosis. Am J Respir Crit Care Med. 2011;184:1048-54.

3. Kakavas S, Mongardon N, Cariou A, Gulati A, Xanthos T. Early-onset pneumonia after out-of-hospital cardiac arrest. J Infect. 2015;70:553-62. 
4. Esteban A, Frutos-Vivar F, Muriel A, Ferguson ND, Peñuelas O, Abraira V, et al. Evolution of mortality over time in patients receiving mechanical ventilation. Am J Respir Crit Care Med. 2013;188:220-30.

5. Esteban A, Anzueto A, Frutos F, Alía I, Brochard L, Stewart TE, et al. Characteristics and outcomes in adult patients receiving mechanical ventilation: a 28-day international study. JAMA. 2002;287:345-55

6. Esteban A, Ferguson ND, Meade MO, Frutos-Vivar F, Apezteguia C, Brochard L, et al. Evolution of mechanical ventilation in response to clinical research. Am J Respir Crit Care Med. 2008;177:170-7.

7. Mongardon N, Kohlhauer M, Lidouren F, Hauet T, Giraud S, Hutin A, et al. A brief period of hypothermia induced by total liquid ventilation decreases end-organ damage and multiorgan failure induced by aortic cross-clamping. Anesth Analg. 2016;123:659-69.

8. Darbera L, Chenoune M, Lidouren F, Kohlhauer M, Adam C, Bruneval $P$, et al. Hypothermic liquid ventilation prevents early hemodynamic dysfunction and cardiovascular mortality after coronary artery occlusion complicated by cardiac arrest in rabbits. Crit Care Med. 2013;41:e457-65

9. Kohlhauer M, Lidouren F, Remy-Jouet I, Mongardon N, Adam C, Bruneval $P$, et al. Hypothermic total liquid ventilation is highly protective through cerebral hemodynamic preservation and sepsis-like mitigation after asphyxial cardiac arrest. Crit Care Med. 2015;43:e420-30.

10. Kohlhauer M, Berdeaux A, Kerber RE, Micheau P, Ghaleh B, Tissier R. Liquid ventilation for the induction of ultrafast hypothermia in resuscitation sciences: a review. Ther Hypothermia Temp Manag. 2016;6:63-70.

11. Tissier R, Giraud S, Quellard N, Fernandez B, Lidouren F, Darbera L, et al. Kidney protection by hypothermic total liquid ventilation after cardiac arrest in rabbits. Anesthesiology. 2014;120:861-9.

12. Hutin A, Lidouren F, Kohlhauer M, Lotteau L, Seemann A, Mongardon $\mathrm{N}$, et al. Total liquid ventilation offers ultra-fast and whole-body cooling in large animals in physiological conditions and during cardiac arrest. Resuscitation. 2015;93:69-73.

13. Wolfson MR, Hirschl RB, Jackson JC, Gauvin F, Foley DS, Lamm WJE, et al. Multicenter comparative study of conventional mechanical gas ventilation to tidal liquid ventilation in oleic acid injured sheep. ASAIO J Am Soc Artif Intern Organs. 1992;2008(54):256-69.

14. Jiang $L$, Feng $H$, Chen $X$, Liang $K$, Ni C. Low tidal volume reduces lung inflammation induced by liquid ventilation in piglets with severe lung injury. Artif Organs. 2017:41:440-5

15. Merz U, Klosterhalfen B, Häusler M, Kellinghaus M, Peschgens T, Hörnchen H. Partial liquid ventilation reduces release of leukotriene B4 and interleukin-6 in bronchoalveolar lavage in surfactant-depleted newborn pigs. Pediatr Res. 2002;51:183-9.

16. Robert R, Micheau P, Avoine O, Beaudry B, Beaulieu A, Walti H. A regulator for pressure-controlled total-liquid ventilation. IEEE Trans Biomed Eng. 2010;57:2267-76.

17. Pohlmann JR, Brant DO, Daul MA, Reoma JL, Kim AC, Osterholzer KR, et al. Total liquid ventilation provides superior respiratory support to conventional mechanical ventilation in a large animal model of severe respiratory failure. ASAIO J Am Soc Artif Intern Organs. 1992;2011(57):1-8.

18. Foust R, Tran NN, Cox C, Miller TF, Greenspan JS, Wolfson MR, et al. Liquid assisted ventilation: an alternative ventilatory strategy for acute meconium aspiration injury. Pediatr Pulmonol. 1996;21:316-22.

19. Avoine O, Bossé D, Beaudry B, Beaulieu A, Albadine R, Praud J-P, et al. Total liquid ventilation efficacy in an ovine model of severe meconium aspiration syndrome. Crit Care Med. 2011;39:1097-103.

20. Nadeau M, Sage M, Kohlhauer M, Mousseau J, Vandamme J, Fortin-Pel-

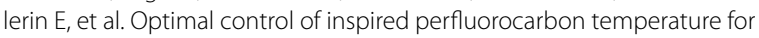
ultrafast hypothermia induction by total liquid ventilation in adult patient model. IEEE Trans Biomed Eng. 2017;64:2760-70.

21. Nadeau M, Micheau P, Robert R, Avoine O, Tissier R, Germim PS, et al. Core body temperature control by total liquid ventilation using a virtual lung temperature sensor. IEEE Trans Biomed Eng. 2014;61:2859-68.

22. Kacmarek RM, Wiedemann HP, Lavin PT, Wedel MK, Tütüncü AS, Slutsky AS. Partial liquid ventilation in adult patients with acute respiratory distress syndrome. Am J Respir Crit Care Med. 2006:173:882-9.

23. Ricard J-D, Iserin F, Dreyfuss D, Saumon G. Perflubron dosing affects ventilator-induced lung injury in rats with previous lung injury. Crit Care Med. 2007;35:561-7.

24. Sage $M$, Nadeau M, Forand-Choinière C, Mousseau J, Vandamme J, Berger C, Tremblay-Roy JS, Tissier R, Micheau P, Fortin-Pellerin E. Assessing the impacts of total liquid ventilation on left ventricular diastolic function in a model of neonatal respiratory distress syndrome. PLOS ONE. 2018;13:e0191885.

25. Sage M, Nadeau M, Kohlhauer M, Praud J-P, Tissier R, Robert R, et al. Effect of ultra-fast mild hypothermia using total liquid ventilation on hemodynamics and respiratory mechanics. Cryobiology. 2016;73:99-101.

26. Rüdiger M, Wendt S, Köthe L, Burkhardt W, Wauer RR, Ochs M. Alterations of alveolar type II cells and intraalveolar surfactant after bronchoalveolar lavage and perfluorocarbon ventilation. An electron microscopical and stereological study in the rat lung. Respir Res. 2007:8:40.

27. Slack DF, Corwin DS, Shah NG, Shanholtz CB, Verceles AC, Netzer G, et al. Pilot feasibility study of therapeutic hypothermia for moderate to severe acute respiratory distress syndrome. Crit Care Med. 2017;45:1152-9.

28. De Luca D, Tingay DG, van Kaam A, Brunow de Carvalho W, Valverde E, Christoph Roehr C, et al. Hypothermia and meconium aspiration syndrome: international multicenter retrospective cohort study. Am J Respir Crit Care Med. 2016;194:381-4.

29. Chenoune M, Lidouren F, Adam C, Pons S, Darbera L, Bruneval P, et al. Ultrafast and whole-body cooling with total liquid ventilation induces favorable neurological and cardiac outcomes after cardiac arrest in rabbits. Circulation. 2011:124:901-11.

30. Brackenbury AM, Puligandla PS, McCaig LA, Nikore V, Yao LJ, Veldhuizen RA, Lewis JF. Evaluation of exogenous surfactant in $\mathrm{HCL}$-induced lung injury. Am J Respir Crit Care Med. 2001;163:1135-42.

\section{Submit your manuscript to a SpringerOpen ${ }^{\circ}$ journal and benefit from:}

- Convenient online submission

- Rigorous peer review

- Open access: articles freely available online

- High visibility within the field

Retaining the copyright to your article

Submit your next manuscript at springeropen.com 